\title{
Un docente revolucionario para la formación artística (decolonial) contemporánea
}

\author{
A revolutionary teacher for contemporary (decolonial) artistic \\ training
}

Roberto JIMENEZ. Universidad Autónoma de Baja California (México)

robertorosique@gmail.com

Resumen: Cualquier propuesta curricular implica la consonancia entre las estructuras educativas (alumno, maestro, escuela, personal administrativo y comunidad) y para el logro, es imprescindible una responsabilidad compartida, nadie menos o más que otro; sin embargo, el papel que representa el docente es trascendental, dado que como mediador es en quien, por lo regular, recae gran parte de la responsabilidad de que el engranaje entre todos los elementos funcione y, específicamente, que los contenidos educativos acordados se cumplan cabalmente. Desde el campo de la instrucción artística (formal o informal) la figura del docente debe evaluarse también bajo estas expectativas de cambio; la disrupción del arte hacia otros espacios obliga a que, quien desempeñe el papel de profesor se vuelque a la búsqueda de rutas libres para que el proceso formativo transforme al alumno (al creador) en un individuo crítico y propositivo; orientándolo a la decolonialidad para que su producción artística deje de depender del aval hegemónico que la ha mantenido invisibilizada. Compromisos todos, que hoy resultan impostergables donde también al arte se le exijan otras responsabilidades más allá de la consabida funcionalidad de emocionar y ser fin monetario; convenios necesarios dirigidos hacia objetivos cada vez más ligados a la realidad social que se vive, con metas que aporten a la edificación de una sociedad diferente, honesta y justa.

Palabras clave: docente revolucionario, colonialidad, arte decolonizado.

Abstract: Any curricular proposal implies the consonance between the educational
structures (student, teacher, school, administrative staff and community) and for
the achievement, a shared responsibility is essential, nobody less or more than 
another; but nevertheless, the role that the teacher represents is transcendental, since as mediator it is in whom, as a rule, a great part of the responsibility falls on the co-ordination between all the elements to work and, specifically, that the agreed educational contents are fulfilled fully. From the field of artistic instruction (formal or informal) the figure of the teacher must also be evaluated under these expectations of change; the disruption of art towards other spaces forces those who play the role of teacher to turn to the search for free routes so that the formative process transforms the student (the creator) into a critical and proactive individual; orienting it to decoloniality so that its artistic production no longer depends on the hegemonic endorsement that has kept it invisible. All commitments, which today are impossible to impose, where art is also required to carry out other responsibilities beyond the usual functionality of emotion and monetary purpose. Necessary agreements directed towards objectives increasingly linked to the social reality that is lived, with goals that contribute to the building of a different, honest and just society.

Keywords: revolutionary teacher, coloniality, decolonized art.

\section{Un acercamiento a la cuestión}

El papel del docente ha sido fundamental en el desarrollo del ser humano, una cuestión inobjetable, manifiesta en los distintos roles asumidos a través de la historia, que ha respondido a las necesidades generadas en una sociedad que transita entre reglas (no siempre equitativas) determinadas por los sistemas en turno; ha desempeñado, específicamente, un accionar supeditado a las exigencias de los modelos curriculares establecidos y ha sido, a la vez, quien ha propiciado cambios para que aquellos modelos restrictivos o inicuos se adecuen al compromiso del papel humanista y revolucionario que da sentido a la educación.

Una larga historia que inicia desde antes del nacimiento de las civilizaciones, pues estas son, a fin de cuenta, el fruto de aquellos que preservaron, analizaron, formularon y compartieron (que bien pueden ser equivalentes del docente) junto con otros participantes de la colectividad, los conocimientos que han trazado el cambio en dichas sociedades.

Cada generación reconoce y cuestiona el actuar del docente, se encumbran hasta hacérnoslo ver indispensables o se desprestigian (a veces de manera infundada y en otras justificables), todo esto develado a la luz de las conveniencias que resguardan intereses específicos; pese a ello, estas condiciones resultan vitales para recomponer lo mal establecido y para reapropiarse de todo aquello que favorece al bien común.

El docente, no importa en qué modelo curricular se desempeñe, invariablemente se le exige la misma disponibilidad y entrega, y será, desde su particular percepción de la vida, quien alimente la tradicionalidad convenida que justifica la formación 
establecida para la permanencia de regímenes colonialistas o se contraponga construyendo rutas hacia la decolonialidad y la equidad social. Un dilema en el que se determina su condición conservadora o revolucionaria.

En la estructura pedagógica de un sistema neoliberal se requiere de un docente proactivo, eficiente que debe educar para le excelencia, ser un facilitador de experiencias de aprendizaje dotando al alumno de herramientas intelectivas, habilidades y destrezas para la competitividad, que en definitiva reducen el proceso formativo a una razón técnico-instrumental, indispensable en la persistencia de un sistema que convierte el progreso en consumismo (el fermento de un capitalismo invariablemente deshonesto); que además, fomenta el individualismo, la competencia que preferencia el "tener" sobre el "ser" (el lucro como fin); condiciones que favorecen las asimetrías como la discriminación del ser humano en todos sus aspectos, las abismales diferencias económicas con sus respectivos demarcaciones socioculturales, sus diásporas y fragmentaciones familiares detonadoras de crisis y alienación. Modelos disciplinares que desde la óptica tradicional promueven la parcelación del conocimiento y las actitudes acríticas; condiciones necesario de visibilizar y replantear desde posturas socialmente más comprometidas.

En una educación tradicional el quehacer del docente tiende a volverse un proceso puramente técnico y mecanicista, condiciones secundarias a la desmotivación y desmoralización que a decir de Canestrari y Marlowe (2005, p.42), lo ha llevado a la pérdida casi total del control sobre su trabajo, y por consecuencia a desempeñarse en un rol disminuido, dócil a los mandamientos de las autoridades, negándose, incluso, a actuar en contra de sus propios juicios y experiencias. Haciendo frente, asevera Peter McLaren (1984, p. 293) a "las normas prevalecientes y a los regímenes establecidos de verdad"; actores que conciben la labor instructiva como una simple tarea instrumental, que se niega a reconocer y asumir su papel histórico de reformador. Ese papel prevaleciente lo convierte en aparejo para reproducir el pensamiento adiestrado y por supuesto, en obstáculo para un desarrollo social equitativo.

Si se tiene claro la necesidad de reformular el papel docente, es indispensable también clarificar desde qué trinchera nos interesa asuma tales cambios, qué valores debemos esperar de la producción artística, pues será completamente diferente aceptarla desde la manufactura tradicional de objetos simbólicos con aquella que persigue sumarle al arte otras responsabilidades ligadas a la realidad social, y si hay el interés primario (que es el de este ensayo) de dimensionar al docente a partir una formación asumida desde la decolonialidad, entendida esta como el proceso a través del cual reconocemos otras historias, otras maneras de ser y estar en el mundo distintas a las lógicas hegemónicas impuestas, que busca restituir la dignidad y valía a aquellos que por imposición fueron y han sido considerados inferiores; su rol implicaría dejar la tradicionalidad por un cambio de estrategia de mayor compromiso con su contexto social. 
Desde esta postura se puede exhortar al docente a que asuma el acto creativo como un medio que libere de trabazones al dicente y lo conmine a proponerlo, tal lo plantea Adolfo Albán (2009):

...como un hecho que in-surge, [como un] decir que se muestra, devela, cuestiona, problematiza e interpela el orden establecido permitiendo al sujeto creador en cualquier instancia de la vida social asumir el compromiso crítico de precisar su lugar de enunciación reafirmando su condición sociocultural, étnica, generacional, de género, de opciones sexuales, religiosas, políticas y reivindicar lo local como un acto de re-afirmación de lo que nos es propio o de lo que hacemos propio. (p. 91)

Un cambio que posibilita transitar con el arte hacia líneas desligadas de las imposiciones que desde intereses particulares seleccionan, premian o castigan. Un cambio que redimensiona la forma de hacer arte animándola a que se convierta en una práctica de-constructiva que nos lleve a desaprender y se cristalice en la posibilidad de decolonizar nuestras mentes, y en la medida que podamos, de la mano de la pedagogía (entendida como la práctica reflexiva del sentido del ser humano), "expresarnos sin miramientos ni ataduras, sin restricciones ni apocamiento y logremos sacar a flote lo que nos constriñe el alma" (Albán, 2009, p. 90). Lo que llevaría, no únicamente producir objetos artísticos sino a recapacitar constantemente sobre nuestra condición humana y sus diásporas opresoras o invisibilizantes.

Una formación que contemple la urgencia de reconocer como cualidad, tal lo sugiere Ramón Cabrera Salort $(2015$, p. 91) “...la producción de objetos sustituida por acciones [...] el abandono de las categorías estéticas tradicionales por nuevas cualidades ideoformales [...] el dominio de lo intertextual en la construcción del discurso y la ruptura con los géneros artísticos tradicionales". Medidas todas que suponen una participación instruccional distinta comprometida con la búsqueda de nuevas alternativas.

Una educación cuyas disciplinas se integren en la praxis donde se involucren las operaciones elementales: sensitivas, visuales, intelectuales y manuales. Ejercicios que de acuerdo con Ramón Cabrera (2015, p. 95) llevan a un comportamiento orgánico sobre los modos de mirar, sentir, manipular, pensar e imaginar de tal manera "que cada disciplina enseñe a construir y deconstruir paradigmas".

Si el cambio provocado por las circunstancias exige replantearse los modelos educativos, sería estéril que en esa preocupación no se considere repensar el actuar docente, a quien siempre se le demandará el cumplimiento de lo curricularmente acordado; es por ello que su figura debe por obligación definirse bajo las expectativas que el cambio exige.

Si el docente enseña básicamente a través de lo que es, mediante su forma de actuar y percibir el mundo, por medio de sus actitudes y valores, así como la manera en 
que se relaciona con el otro y su contexto; independientemente de su experiencia, formación y conocimientos, se requiere de su integridad, de su afectividad, preocupación y empatía con la realidad social que vive, para que pueda asumir su participación en el compromiso por la transformación social, política y económica de su contexto. Sin estas actitudes desprendidas de la individualidad sería sumamente difícil un actuar justo y efectivo.

Cualquier propuesta curricular implica la consonancia entre las estructuras educativas (alumno, maestro, escuela, personal administrativo y comunidad) y para el logro, es imprescindible una responsabilidad compartida, nadie menos o más que otro; sin embargo, el papel que representa el docente es trascendental, dado que como mediador es en quien, por lo regular, recae gran parte de la responsabilidad de que el engranaje entre todos los elementos funcione y, específicamente, que los contenidos educativos acordados se cumplan cabalmente.

Desde el eje de la instrucción artística (formal o informal) la figura del docente debe evaluarse también bajo estas expectativas de cambio, la disrupción del arte hacia otros campos obliga a que quien desempeñe el papel de profesor se vuelque a la búsqueda de rutas libres para que el proceso formativo transforme al alumno (al creador) en un individuo crítico y propositivo; un compromiso impostergable donde también al arte se le exijan otras responsabilidades más allá de la consabida funcionalidad de emocionar y fin monetario.

\section{Del protagónico instructor renacentista al docente versátil de la actualidad}

De aquella figura mítica inalcanzable del instructor renacentista a la del docente que diversifica su enseñanza en la interdisciplina hasta convertirse también en un discente, transcurren siglos, en donde vemos, de igual forma, como la imagen del profesor se diluye ante las exigencias de un mercado que prioriza la belleza y la emoción (el consumismo) ante otras potencialidades del arte; una vieja historia que permanece vigente, y que, sin pretextos, demanda replantearse.

La formación artística tradicional ha transcurrido adecuándose desde sus contextos y potencialidades a los enfoques pedagógicos establecidos para la educación en general, conformando sus propios modelos ${ }^{1}$, los que podemos diferenciar a partir de la experiencia del Renacimiento en donde se consideró importante otorgarle un distintivo al arte, retomando las viejas clasificaciones griegas, las que demarca e institucionaliza en artes manuales (artes vulgares) que requieren de las habilidades y exigen del esfuerzo físico, y las intelectuales (artes liberales) que demandan del intelecto y el pensamiento libre; diferencias que se adoptarán en los gremios

1. Modelo Mimético, Logocéntrico, Expresionista, Iconocéntrico, Neoexpresionista, Postmoderno, Sociocultural, Comunitario, Colaborativo Virtual y Alternativo Crítico y Emancipador/ Decolonial (Rosique, 2019). 
pictóricos establecidos de los que posteriormente emanarán las academias ${ }^{2}$; en donde el papel del docente será reconfigurado.

La formación generada en los talleres dirigida por el maestro quien distribuía las faenas que iban de lo más elemental como la limpieza del espacio, pinceles y toda herramienta de trabajo, la preparación de pigmentos y lienzos, etc., hasta la participación supervisada en la elaboración de las obras que se realizaban para un pedido en particular. Pasos que requerían de una estancia prolongada en el taller hasta la liberación otorgada por el instructor al considerar al discípulo apto para continuar por su cuenta, y la evaluación por una comisión de pintores que concedían el permiso (oficial) tras un riguroso examen de sus habilidades (como la creación de la obra maestra) para establecerse de manera independiente. Un proceso formativo cuyo saber era transmitido mediante la imitación y la repetición de esquemas establecidos en relación al objeto en cuestión a representar (Modelo Mimético) ${ }^{3}$.

Academias que veremos consolidarse como tal hasta el siglo de las luces, y en donde encontraremos una mayor formalización de la instrucción artística y la figura del profesor, ya para ese entonces protagónica y difícil de superar, que seguiría siendo por mucho tiempo guía y fuente de inspiración para el discípulo.

Será hasta el siglo XVIII cuando las Bellas Artes ${ }^{4}$, propiciadas por el gusto refinado que demarcaba lo culto de lo popular, le exigirán al pintor una educación formal. Sus seguidores convencidos de que el arte es sinónimo de civilización, consideraban que la sensibilidad y el sentimiento de lo bello en él, puede aprenderse y, por tanto, enseñarse desarrollando la destreza y el gusto.

Con el surgimiento de la Academia de Bellas Artes, el arte se constituye como un ejemplo de la racionalidad ilustrada determinada por estrictas leyes formales de la perspectiva, el manejo pertinente del color, la proporción y la composición,

\footnotetext{
2. Ante la insistencia del pintor por separarse de los gremios artísticos medievales, representativos de oficios reconocidos como mecánicos, que poseían el control de las relaciones laborales, surgen las academias de arte que establecen sesiones regulares sobre problemas de carácter teórico como el de la nobleza de la pintura y la superioridad de ésta ante la escultura, entre otros; realizaban talleres de dibujo y pintura que dignificaban la enseñanza y consecuentemente la actividad del artista. La aceptación y la demanda de este nuevo sistema educativo, ahora bajo el control del Estado tendrá, además, la autoridad de otorgar títulos (un poder arrebatado a los gremios) y el consecuente control ideológico sobre la profesión, pues únicamente sería pintor aquel que cumpliera con los requisitos impuestos por los criterios académicos. Un instrumento de singular poder que con el paso del tiempo sería ejercido con la discrecionalidad que a la academia y al sistema convenía, y que manipularía los estilos y las tendencias artísticas hasta prácticamente fines del siglo XIX. (Rosique, 2019).
}

3. El Modelo Mimético, centrado en el valor del objeto, en la destreza técnica y la instrucción; el eje en torno a quien circundaba todo era el maestro, al que debía emularse y reverenciarse, y el objetivo último: el logro de la representación mimética de la naturaleza.

4. Bellas Artes, término que emplea Charles Batteaux (1713 - 1780) un filósofo, humanista francés por vez primera en 1774 con el que engloba la pintura, la escultura, la música, la danza y la poesía, posteriormente será añadida la arquitectura y que, en 1911, Rocciotto Canudo incluirá el cine como el séptimo arte. El término Artes Nobles como sinónimo de Bellas Artes lo veremos aparecer en 1920, en pleno apogeo de las vanguardias históricas. 
que acuerdan la noción de belleza. "La Academia, expresan Arthur Efland, Kerry Freedman y Patricia Stuhr (2003, p. 64), estaba encargada de transmitir los principios del arte a sus miembros por medio de conferencias y lecciones impartidas a los estudiantes a través de dibujos tomados del natural". Se instruía al pintor en el perfeccionamiento técnico que lo llevará al logro fiel del modelo.

Es posible aseverar que, al cierre del siglo XIX, en que comienza a considerarse que la calidad de la obra de arte dependerá de la genialidad del artista más que de la destreza y la ejecución, cuando el papel preponderante del maestro se diluya dando lugar a un modelo formativo (Expresionista) ${ }^{5}$, que a decir de Imanol Agirre (2005) destituye al aprendizaje y su relación con la cultura a cambio de la libre expresión, de la espontaneidad original y la creatividad. En otras palabras, un enfoque que fundamenta, su metodología en la libertad creativa ante la instrucción.

Las academias artísticas del siglo XIX seguían dependiendo en absoluto del mecenazgo del Estado, el religioso y la burguesía; por tanto, las reglas se establecían en concordancia con el sistema. Al cierre del siglo, el arte bajo el control simulado en los salones artísticos oficiales parisinos, será cuestionado y rechazado tanto por la permanencia de las normas añejas de la Academia como por su función instrumental controlada por el Estado. Comenzaba a experimentarse cambios sustanciales en el arte, el Impresionismo será la pauta que llevaría a la odisea de las vanguardias históricas.

En ese espíritu de independencia suscitado por las vanguardias germinarán los talleres promovidos por los artistas en los que se respiraba, en la enseñanza, un aire libre, experimental y aun cuando la figura del instructor no desaparece y su protagonismo es cada vez menor, el distanciarse de la Academia había sido en realidad, la necesidad de independizarse del control del Estado.

Un momento particular en la enseñanza de las artes puede verse en las postrimerías de la Primera Guerra Mundial cuando surge la idea de ligar el arte con objetos o productos cuya función utilitaria respondía a las necesidades crecientes del progreso; la Escuela de la Bauhaus es un buen ejemplo de ello, donde la formación del artista se centraba en los principios arquitectónicos, escultóricos, pictóricos y textiles, que priorizaba la funcionalidad y el diseño ${ }^{6}$. Una estrategia que Eisner (2004) relaciona con la solución de problemas concretos, en que el papel del docente se aboca a proponer metas para el logro de un fin utilitario; es decir, será quien presenta el

5. El Modelo Expresionista, cuya acción formativa estaba centrada en el sujeto y la esencia de la práctica artística consistía en expresar y transmitir sus emociones, en ser resonancia de los estados de ánimo y los sentimientos. Se concebirá el arte como la expresión más genuina de lo íntimo del ser humano y el hecho artístico será por tanto subjetivo.

6. Una fórmula, por cierto, que permitió fusionar la labor del artista con la del artesano dejando a un lado aquella separación renacentista que categorizaba la producción artística como un distingo social y de intereses. 
problema y los estudiantes buscarán la solución del mismo. Un periodo que, a decir de Belver (2011) la identidad del artista creador va perdiendo fuerza.

A partir de la mitad del siglo pasado veremos un replanteamiento de la educación con la aprobación en el Congreso de los Estado Unidos de Norteamérica, la Ley de Educación Nacional para la Defensa que fomentará las matemáticas y la ciencia en general, y bajo el supuesto que el estudiante no aprovecha al máximo sus estudios por no tener visión de conjunto, se aprueba que el currículo debe constituirse por disciplinas. Esto también dará paso a una reestructuración de la educación artística. Gilbert Clark, Michael Day y Dwaine Greer (1987), fundamentan, bajo estos principios, el proyecto de Educación Artística Basado en Disciplina (DBAE: Discipline Based Art Education.), en el cual la producción debe acompañarse de la teoría del arte, crítica y del disfrute del arte entendiendo las bases de su pensamiento (estética). El rol del docente inicia un nuevo camino, el de la especialización para poder protagonizar estos roles diferenciados.

La entrada de la postmodernidad que llevará a cuestionar lo infructuoso de la idea moderna de correspondencia entre representación y objeto; producirá también modificaciones curriculares, ajustándola a la concepción que se tienen del producto artístico. Para Efland, et al (2003, p. 126), “...el arte es una forma de producción cultural destinada a crear símbolos de una realidad común”. Bajo estas ideas se plantean reciclar contenidos y métodos anteriores; ofrecer minirrelatos de formas artísticas marginales; homologar el saber artístico; utilizar la deconstrucción para practicar distintos puntos de vista y reconocer la múltiple codificación de la obra de arte en los diferentes sistemas simbólicos. Un modelo denominado Postmoderno ${ }^{7}$ que exigía de un docente instruido y especializado, un aspecto que determinará la relevancia de la formación artística convirtiendo la credencialización en una medida para justificar posiciones; un recurso aprovechado igualmente para la coerción y el control.

Encontraremos también otros planteamientos pedagógicos fundamentados en la realidad que se vive, que reconocen las necesidades del cambio y que proponen ver y entender el arte, no como una singular actividad humana, sino como hecho cultural cuyas bases se asientan en lo visual. El objetivo de esta propuesta de educación de las artes (Modelo Sociocultural), radica en aportar fundamentos a los estudiantes para comprender críticamente los mundos sociales y culturales en los que se producen sus relaciones. El docente es en este modelo un personaje rodeado de intelectualidad pues gran parte de su enseñanza se alimenta de las teorías artísticas prevalecientes; un profesor instruido que replica los enfoques

7. Modelo Postmoderno, caracterizado, entre otras cosas, por cuestionar la idea moderna de correspondencia entre representación y objeto. Propone para ello ofrecer minirrelatos de formas artísticas marginales; hacer el ejercicio del poder en homologar el saber artístico; utilizar la deconstrucción para practicar distintos puntos de vista y reconocer la múltiple codificación de la obra de arte en varios sistemas simbólicos. 
conceptuales y socioculturales existentes como un camino lógico para la obtención del logro.

Los nuevos campos creativos comenzarán a dirigir sus indagatorias a otras direcciones y sus propósitos educativos hacia esa nueva forma de producir en la que lo conceptual, lo político en el arte y lo comunitario se posesiona del mundo creativo; adquiriendo de esa manera una mayor presencia como práctica artística y visualizándose también como ruta asequible y prometedora (Modelo Comunitario). Un enfoque que involucra el compromiso social, así como la idea del poder transformativo y emancipatorio de la educación; aquí, igualmente, lo colaborativo se redimensiona y adquiere su valor de cambio en la medida que los objetivos se dirigen a la búsqueda de alternativas para el buen vivir.

Al profesor en este modelo colaborativo se le confiere el valor de instructor o guía que imbuido en ideas humanistas (y socialistas) propone prácticas artísticas sustentadas en proyectos, los que serán fácilmente adecuados a la imagen democrática de los gobiernos en turno, llevando al arte a espacios marginados como una forma de remedio social y que debido a los apoyos reducidos y por lo regular efímeros de sus patrocinadores se convierten procesos difíciles de reproducir y por tanto de un impacto más prolongado en los cambios sociales previstos durante la ilusionada elaboración de los propósitos.

El Internet, traspasará los muros escolares e invertirá la asimetría educativa permitiendo pasar del monopolio a la liberación del saber; lo que supone la posibilidad de una mejor distribución y reciprocidad entre los sujetos que producen y consumen los distintos saberes que circulan en la red. La interacción con los medios digitales los alumnos dejan de ser pasivos consumidores de conocimientos para ser activos productores de él. Una educación (Modelo Colaborativo Virtual) que ya no estará centrada en las motivaciones del docente por enseñar sino en las motivaciones de los alumnos por aprender. En donde el aprendizaje es llevado a cabo mediante la observación y la imitación, que requiere, por supuesto de un modelo para reproducirse, en la cual el aprendiz se convierte en maestro a través de la observación, imitación y exploración; un aspecto que aquí es redimensionado por el potencial colaborativo y el libre albedrio que fomenta estos nuevos formatos tecnológicos. Modelos en los cuales la figura del docente es replanteada, su papel protagónico lo asume el alumno, no obstante, sigue siendo un representante (que no desaparece), pues quienes estructuran los planes de estudio finalmente siguen siendo ellos.

Contribuciones importantes, como hemos visto, que resultan asertivas para el contexto en donde han sido planteadas y de las que, para la elaboración de cualquier proyecto educativo, tendrían que ser consideradas muchas de las propuestas y métodos que establecen. Sin embargo, desde la realidad de los países periféricos o tercermundistas, apegarse en estricto a ellas no resulta una solución, pues de ser así 
sólo perpetuarían su condición dependiente, una forma recurrente de invisibilizar sus potencialidades, las que sólo serán reconocidas en función del apego a las reglas establecidas; de ahí que cualquier vocación de cambio real, apremia el desprendimiento de estas rémoras e ir más adelante, asumir un nuevo papel repensando el arte, y por supuesto la educación artística y sus actores, en particular la del profesor que debe ampliar su visión sobre los objetivos del arte, develando en él un mayor compromiso social como sendero a explorar por el dicente; que implica, además, una medida para entender y aceptar la decolonización como recurso para revelar la cultura que a pesar del velo ancestral que la ha cubierto también ha generado conocimiento. En otras palabras, que pongan en cuestión y debatan, como expresa Aníbal Quijano (2000) ${ }^{8}$ :

...la colonialidad del poder, esencia de la discriminación racial; la colonialidad del ser, que se ejerce por medio de la inferiorización, subalternización y la deshumanización, y la colonialidad del saber, específicamente del eurocentrismo que como perspectiva única del conocimiento descarta la existencia y viabilidad de otras racionalidades epistémicas y otros conocimientos. (p. 21)

Pues estas condiciones, como enfatiza el autor, siguen siendo la base misma de nuestros problemas de identidad, como país, nación y Estado; condiciones ineludibles para cualquier proceso educativo formal o informal que persiga la instrucción de individuos integrales, críticos y libres; en el arte no existen razones para desdeñar estas realidades.

Frente a esta situación del pensamiento globalizado, Boaventura de Sousa Santos (2006, pp. 23-29), propone repensar la teoría crítica de las ciencias sociales y humanas que corporifican los contenidos educativos, denunciando el monopolio de las lógicas dominantes, que, a decir del autor, se manifiestan en cinco monoculturas: 1. La de producción de inexistencia, de ausencia, que es la ignorancia; 2. La del tiempo lineal, aquella que prima la idea de que la historia tiene un sentido, una dirección, en donde los países desarrollados van adelante; 3. La de la naturalización de las diferencias que ocultan jerarquías, de las cuales la clasificación racial, la étnica, la sexual y la de castas en India son hoy las más persistentes; 4. La de la escala dominante, que asume que lo global y universal es hegemónico, lo particular y local no cuenta, es invisible, descartable, desechable; 5. La monocultura del productivismo capitalista, aplicable tanto al trabajo como a la naturaleza, cuya idea que el crecimiento económico y la productividad mensurada en un ciclo de producción determinan la productividad del trabajo humano o de la naturaleza, y todo lo demás no cuenta; es decir, todo lo que no es productivo en este contexto

\footnotetext{
8. La colonialidad del poder es una estructura hegemónica global de poder y dominación que articula raza y trabajo, espacios y personas, de acuerdo con las necesidades del capital y para el beneficio de la raza superior. La colonialidad del saber, implica la negación de la producción intelectual alter (indígena, afro, chicana, femenina, etc....) como conocimiento (Walsh, 2007), en otras palabras, desde la imposición del eurocentrismo como la única forma de conocer el mundo. La colonialidad del ser, un concepto desarrollado por Maldonado-Torres (2007), es la dimensión ontológica de la colonialidad que se afirma en la violencia de la negación del Otro.
} 
es considerado improductivo o estéril. Monoculturas que habitan de forma natural en la educación y generan el epistemicidio, para lo que propone cinco ecologías de la experiencia y del conocimiento, ${ }^{9}$ con el fin de superar el monocultivo de estas lógicas referidas.

Reflexiones indispensables para la conformación de pedagogías decoloniales, en las que se asume el protagonismo de un docente emancipado que invita, asimismo, a pensar la educación artística desde la decolonialidad estética (aiesthesis decolonial), ${ }^{10}$ aquella que a decir de Pedro Pablo Gómez (Gómez, et al, 2016, p. 125), "no se agota con la crítica a la estética, con mostrar el racismo, el patriarcado, el eurocentrismo, y el sexismo que se esconden en las grandes teorías estéticas o en la historia del arte". Cuyo papel central se ocupa también de entender cómo opera la estética hegemónica que dicta, selecciona y sanciona invisibilizando otros saberes.

Una aiesthesis abierta a otras estéticas, incluso, a la occidental, plural y directa en la que pueden establecerse diálogos inter y transestéticos ligados a proyectos que buscan la superación de la colonialidad global. (Gómez, et al, 2016, p. 127).

Una aiesthesis que pugna por restablecer la emancipación de los pueblos colonizados; de ahí su estrecha relación con la decolonización del poder, del ser y del saber. Aesthesis que busca, expresan Mignolo y Gómez (2012, p. 9), “...descolonizar los conceptos cómplices de arte y estética para liberar la subjetividad y que comienzan por aquello que el arte y las estéticas occidentales implícitamente ocultan: la herida colonial"

9.1.Ecologíadelossaberes: exponequenohayignorancianisaberengeneraloenabstracto. Todaignoranciaesignorantedeuncierto sabery todo saber es la superación de una ignorancia particular, en un diálogo de saberes y conocimient os, incluidos los científicos. 2. Ecología de las temporalidades: que invita a abrirse a otras formas de pensar el tiempo, más allá de la progresión lineal e irreversible que se prioriza en la modernidad occidental. El presentenopuede serun simpleinstante fugazentre el pasadoyel futuro. 3. Ecología de los reconocimientos: en a que se procura una nueva articulación entre el principio de igualdad y el de diferencia, abriendo la posibilidad de diferencias iguales a partir de reconocimientos recíprocos. 4.Laecologíadelastrans-escalas:dondecabelaposibilidaddearticulardiferentesanálisisdeescalaslocales, nacionalesyglobales, porque las escalas y las cartografías de los fenómenos no coinciden necesariamente en un mismo plano epistémico y fenoménico. 5. La ecología de las producciones: en donde es posible recuperar y valorar otros sistemas alternativos de producción (tradicionales o modernos), que la severidad de la producción capitalista ha ocultado o desacreditado para subordinarlos.

10. La palabra aiesthesis, cuyo origen, explica Walter Mignolo (2010), es el griego antiguo, será aceptada sin modificaciones en las lenguas modernas europeas y cuyos significados girarán en torno a vocablos como "sensación", "proceso de percepción" (visual, gustativa o auditiva) y a partir del siglo XVII, el concepto aiesthesis será restringido y en adelante, pasará a significar "sensación de lo bello". Esta operación cognitiva, explica Mignolo, constituyó la colonización de la aiesthesis por la estética. "Así, concluye el autor, la mutación de la aiesthesis en estética sentó las bases para la construcción de su propia historia, y para la devaluación de toda experiencia aesthésica que no hubiera sido conceptualizada en los términos en los que Europa conceptualizó su propia y regional experiencia sensorial". (Mignolo, 2010, p. 14). De ahí que, si bien como principio inaugural pretendía descolonizar la estética para liberar la aiesthesis, una década después el propio Mignolo redimensiona aclarando que si lo aesthésico nos impregna y está en todo lo que hacemos; liberar la aiesthesis de la estética des-cubre la geopolítica del sentir, pensar, hacer, creer y la extrae también del imaginario abstracto del sujeto moderno, despegado de las energías geopolíticas gestionadas por la matriz colonial del poder. [...] Por eso lo decolonial aesthésico no consiste en describir, interpretar, hablar de "arte decolonial" o de los y las "artistas decoloniales" ni ya tampoco de "estética decolonial" sino que son nuestros (los organismos auto-llamados humanos) decires en todos los ámbitos disciplinario y vivenciales donde lo aesthésico tiene su morada (Mignolo, 2019, pp. 26-29) 
La práctica pedagógica alternativa, al utilizar la aiesthesis decolonial, refiere Rolando Vázquez (2016), posibilita, entre otras cosas, que los estudiantes se hagan conscientes de cómo participan en las estructuras de dominación y se abre también la oportunidad de que experimenten otras lógicas, otras formas de habitar y de vivir el mundo, de relacionarnos con él y con nuestro propio cuerpo, incluso, con la naturaleza y el cosmos.

De ahí la relevancia de un currículo diferente, disyuntivo de la tradicionalidad que ha caracterizado a los modelos convencionales repetidores de esquemas que perpetuán sistemas; que instaure sus bases en la pedagogía crítica para establecer en la praxis una consciencia propositiva y crítica con la cual lograr acciones constructivas en la sociedad; que asuma lo emancipador desde la visón freireana, más allá de la autonomía y la igualdad, a fin de concebir un mundo más abierto y justo para todos, sostenido en relaciones sociales basadas en la solidaridad y al mismo tiempo cuestione y anteponga a lo decolonial que, como utopía concreta redimensione los valores de nuestra cultura ancestral y contemporánea, que nos permita recobrar la visibilidad de lo que somos, que la mirada occidental desde tiempos inmemoriales oculta y exotiza, y por supuesto, crear nuevo conocimiento libre del yugo (colonial), abrirse a otras fronteras para refundamentar el saber, alimentado de la enorme riqueza cultural que nos conforma como latinoamericanos y sujetos universales. (Modelo Alternativo Crítico/Poscrítico, Emancipador/Decolonial) (Rosique, 2019)

Así pues, ante un compromiso de esta naturaleza es necesario enfatizar que se torna indispensable contar con profesores que se desliguen de la tradicional misión en la que él, sabedor de todo, le corresponde organizar el conocimiento, aislar, elaborar lo que debe ser aprendido, y trazar de esa manera el camino por el que transitarán los alumnos; librarse de aquel que considera al conocimiento como único y definitivo, y prioriza la transmisión académica de conocimientos como el medio idóneo de enseñanza pues presume que saber es poder. Así como de aquel otro que desde la mecanización y memorización busca la reproducción de los contenidos; da por hecho que la mejor manera de preparar al estudiante para la vida es formar su inteligencia, sus posibilidades de atención y de esfuerzo, otorgándole gran importancia a la transferencia de la cultura y de los conocimientos, pues cree útiles para ayudarlos a conformar una personalidad disciplinada. También ese otro que considera que si la pretensión es lograr el dominio del oficio o la profesión, supone la formación como un proceso ajeno a la voluntad, intereses y necesidades del alumno. Un papel de esta naturaleza no tiene cabida en la formación de individuos autónomos, críticos y propositivos.

\section{La necesidad de actores educativos diferentes}

Los conceptos puestos a la luz en el título de este ensayo, indivisibles y consustanciales en su accionar: docente revolucionario y la formación artística contemporánea (decolonial), son el eje en que se justifica. El primero es aquel que asume su rol 
educativo comprometido con la construcción social incluyente y equitativa, una responsabilidad que se adquiere desde la convicción de la justicia y el bien social, en donde el actuar está constantemente en consonancia con lo colaborativo, con la crítica y la propuesta, en el respeto y la empatía; en tanto que la formación artística contemporánea, da por sentado el hecho del limitante papel del arte cuando éste se produce únicamente como un bien simbólico, de entre el amplísimo campo en que se ha expandido fuera de las formas estéticas y conceptuales que circundan al objeto artístico; este ha derivado hacia disciplinas disimiles y sobre todo hacia objetivos cada vez más ligados a la realidad social que se vive, comprometidos en metas que aporten a la edificación de una sociedad diferente, honesta y justa. Posturas que no pueden imaginarse sino desde fuera de las lógicas establecidas, desde la decolonialidad como una medida que ayudará a validarnos por lo que somos no por lo que otros dicen que somos.

Para tal comisión es necesario el profesor que tenga clara la altísima responsabilidad que implica el cargo, una persona invariable en su papel igualitario, liberador de la sumisión atávica; redimida de la jerarquía asignada en el pasado como dictador de cátedras, con una consciencia plena de lo imperativo del cambio. Se requiere pues, de un maestro emancipado (con todas las implicaciones que el término supone), que como agente movilizador aborde la enseñanza con recursos didácticos adecuados a las exigencias y necesidades educativas reales requeridas.

El maestro en esta nueva pedagogía tendrá que jugar un papel completamente distinto al establecido en el pasado, dejar a un lado el monopolio del conocimiento (en el sentido de que no lo comparten o lo hacen parcialmente), el ser, únicamente, trasmisor de información y asumir el compromiso de saber escuchar para que actué como estímulo y catalizador de las ideas del dicente. Sin más opciones, tendrá que ser también reflexivo, poseer la suficiente conciencia y perspicacia para analizar las formas de vida contemporáneas y que pueda discutirlas con el estudiante para acrecentar (en ambos) su responsabilidad y sentido crítico.

Debe lograr que lo pedagógico sea más político, atendiendo, tal lo expone Giroux (1997), tanto a las condiciones a través de las cuales enseñan, como a lo que significa aprenderdeunageneraciónque estáexperimentandolavidaenuna formamuy diferente de las representaciones que ofrecen las versiones conservadoras de escolaridad, y en la medida, agregaría, de cuestionar la iniquidad, así como las políticas complacientes y advenedizas florecientes en esta sociedad contemporánea del espectáculo.

Un docente que dé voces a todos los discursos generados en el aula, sobre todo a los que se oponen a sus puntos de vista; ello favorecerá procesos democráticos reales que harán factible que los estudiantes se involucren en la generación de su conocimiento; así como también en las negociaciones de los contenidos y las evaluaciones. Una medida sustancial para que éste pueda abordar críticamente la construcción de su propia subjetividad. 
Un maestro, como propuso Jacotot (2008) y plantea también Rancière (2007), que se sitúe en un nivel de igualdad de conocimiento con el dicente y su papel sea el de movilizar la voluntad del alumno, pero no de enseñarle nada en el sentido de explicar. El docente "explicador" por muy progresista que parezca contribuye a la desigualdad ${ }^{11}$, como también -añadiría- a la dependencia y a la formación de individuos acríticos y conformistas; pues la explicación se convierte en instrumento de sutil imposición y dominación del docente al estudiante.

Un rol que difícilmente puede ponerse en práctica sin la humildad de saberse también aprendiz; una condición indispensable que Paulo Freire (1974, p. 53), reiteró con entera claridad: "El profesor deja de ser meramente quien enseña para ser el mismo enseñado en el diálogo con los alumnos, quienes, a su vez, mientras son enseñados, también enseñan...". Se requiere pues de un docente capaz de aceptar que sus estudiantes pueden ayudarlo a transformar sus propios códigos teóricoconceptuales sobre la práctica pedagógica y la vida cotidiana. Un acontecimiento, si bien centrado en el concepto de enseñanza, que en apariencia se contrapone a lo propuesto por Jacotot, pero que al ser planteado, como lo hizo Freire, desde la correspondencia y humildad en donde se reconoce al otro para actuar en igualdad, predispone a entrar en comunión en una franca acción dialógica y justa.

Es necesario un profesor que tenga la capacidad de cambiar el paradigma personal y del alumno, de ver en el otro el medio para lograr el conocimiento. La fórmula colonial que ha subsistido haciendo creer que se requiere del conocedor, del experto para instruir, ha sido una lógica fundada en la importancia, el acúmulo de saberes y la domesticación del que se sabe menos. Por ello la importancia de superar esa educación basada en la conquista del saber y de los estudiantes.

Es imperioso un docente que ejemplifique mediante la disonancia, la discusión y el diálogo; un docente "ironista" dice Richard Rorty (1989), en la medida que el ejemplo pueda diseccionarse desde cualquier óptica, el sarcasmo, incluso, cuando con este se recrea el hecho impuesto y visibiliza lo mal intencionado del mismo. Enredador, instigador, abierto a la emergencia y generador de relaciones inéditas, propone Agirre (2005). Que utilice la complicación como recurso para valorar lo elemental, la provocación como medida de análisis, lo nuevo como parámetro comparativo de lo existente; recursos válidos para el pensamiento disidente y efectivo si ello induce a reflexiones no imaginadas. Un docente que desarrolle una constante resistencia cultural, así como una alerta y cuestionamiento a su propia certidumbre y a la establecida, como una forma de poner en evidencia las alternativas.

\footnotetext{
11. Todo individuo (adulto o niño), decía Jacotot, tiene la capacidad de instruirse solo, sin maestro. Quien quiere puede, insistía, y afirmaba que es posible enseñar lo que se ignora si uno es capaz de impulsar al alumno a emplear su propia inteligencia. Y el hecho que el maestro ignore realmente lo que está en su voluntad enseñar es una garantía de que no subordinará la inteligencia ignorante del alumno a la sabia del maestro. Así, las dos inteligencias (maestro y alumno) dependen a su vez de una tercera: la del libro o cualquier otro elemento que funcione como sistema de referencia (Rancière, 2007).
} 
Un docente que posea una instrucción interdisciplinar y u na sólida formación pedagógica, que se mantenga actualizado en los temas que aborda en sus clases y comprometido al reajuste constante de la propia concepción de la enseñanzaaprendizaje; que induzca a la creación compartida con los alumnos de nuevos modelos o ejercicios nacidos de las necesidades existentes.

Un docente que, sin menoscabo, posea también una profunda sensibilidad hacia el medio ambiente y la sustentabilidad, de tal forma que pueda, junto a sus alumnos, poner en práctica proyectos comprometidos con el entorno universal, pero sobre todo que enlacen con las necesidades de la realidad social más cercana.

Maestros que se posesionen del papel de actores sociales inclusivos, mediadores del conocimiento y de prácticas culturales, que compartan el escenario con otros representantes de la comunidad; no únicamente por las implicaciones de lo colaborativo, sino como una forma de volver realidad la inter y transdisciplina en el desarrollo formativo.

Se requiere de profesores que tengan claro que la escuela ya no puede seguir siendo el espacio donde se reproduce exclusivamente lo que la sociedad considera como respuestas válidas y actos legítimos, y en donde se aprende lo que el sistema ha determinado como verdadero; pues convertidas estas acciones en normas inamovibles invalidan otras lógicas y legitiman por conveniencia únicamente lo aprobado con antelación, “...olvidamos que vivimos en mundos interpretativos y que todo examen crítico al sentido común nos conduce inevitablemente a reconocer que la supuesta solidez que el sentido común nos ofrece, en rigor, se sustenta en el vacío, o quizás mejor, en la confianza y sensación de solidez que nos confiere el consenso" (Echeverría, 2009, p. 218). Sin embargo, si el consenso fomenta y mantiene las desigualdades sociales y culturales del contexto, debe obligadamente abrirse a otras formas de pensar.

Un maestro que estimule al alumno a percibirse como seres inacabados, inconclusos (Freire, 2009), para que, con la búsqueda permanente, asuman conscientemente su autonomía y puedan comprobar su capacidad transformadora. Que acepte la incertidumbre como medio para que, con la apertura desprejuiciada de la investigación, pueda dilucidar y replantear sus certezas.

Así, el papel del docente requiere de un severo replanteamiento y su objetivo es fomentar la autonomía para que el dicente construya su propio conocimiento y se emancipe. Los educadores críticos, escribía Henry Giroux (1990) tiempo atrás, "están empezando a construir un nuevo lenguaje inspirado, entre otros, en el proyecto descontruccionista de Derrida, en el combate hermenéutico de Gadamer, en la reconstrucción psicoanalítica de Lacan, en la anarquía textual de Barthes y en la idea de poder e indagación de Foucault" (p. 216). 
Un lenguaje que enriquecido desde estas posturas ya hace suponer el cambio y sus alcances; pero imaginado desde el pensamiento del Sur implica otras responsabilidades, entre estas, la de educar bajo la premisa obligada de la decolonialidad. Una ruta invariable, si en verdad queremos formar para la emancipación y sobre todo si aspiramos realmente a construir, desde las periferias, conocimiento alternativo.

Los educadores críticos ( $\mathrm{si}$ es que se asume ese rol con la responsabilidad pretendida) de los países no hegemónicos, hoy deben estar ejercitándose en esos principios propuestos por Giroux hace tres décadas; pero, ante todo, deben considerar como columna vertebral, la premisa de Freire (2006) de educar para la emancipación; al igual que educar "para impugnar la exclusión y reconstruir el tejido social construyendo el empoderamiento de los relegados..." (Mejía, 2014, p. 117). Sin estas posturas que provienen de la realidad de los colonizados resulta difícil comprender el verdadero compromiso crítico y social del rol docente. Un compromiso pendiente que en arte debe también asumirse sin temor a las etiquetas que marginan.

Es necesario el docente formado en la comprensión crítica y reflexiva sobre las subjetividades, con un claro compromiso comunitario, esto asegura un operar compartido y neutral donde todas las voces tengan sentido. Un docente comprometido a educar en la diversidad implica un alto sentido de apertura y empatía, ello supone "aceptar el encuentro, aprender el lenguaje del otro, correr el riesgo de la confrontación, juzgar al otro no en relación conmigo sino a partir de sus propios criterios" (Naïr, 2006, p. 24); pues a decir por este autor, las medidas para juzgar la otra cultura no se encuentran en nuestra propia cultura, sino que se encuentran en esa otra cultura.

Un docente cuya labor debe estar exenta de cualquier tipo de significación redentora, la laicidad como principio de equidad debe prevalecer por sobre cualquier imposición dogmática; procurando, como verdadera responsabilidad de su accionar, evitar convertir sus postulados en dogma.

En la tradicionalidad de un currículo común el discurso político parece aceptarse únicamente dentro de las áreas de estudio avocados a las ciencias políticas y morales, jamás en las pedagogías artísticas o creativas, no ha habido aparentemente razón para ello, sobre todo si la meta formativa es desarrollar habilidades para la elaboración de objetos de arte simbólicos y asequibles al mercado. No obstante, podemos ejemplificar momentos históricos (fugaces si se quiere) donde anteponer lo político al arte tuvo su sentido, así como, en cierta forma, puede verse en la postmodernidad, en el campo ampliado de la producción artística, específicamente en los discursos que conforman lo enfoques comunitarios. Pese a todo, dada la relevancia del mismo, la inclusión en campo educativo se hace imperativo, y aunque incomode aceptarlo no hay justificación para negarse. 
Educación y política no pueden desligarse, la política necesita de la educación y esta de la política para avanzar en su estructura, desarrollo, actuación y resultados. En una época de creciente cinismo político y de decepción con las instituciones tradicionales, las escuelas no pueden hacer caso omiso de la educación política; la formación artística y el arte, por su lado, tampoco tienen excusa para no hacerlo.

Todo arte es político por ser consecuencia directa de los intereses económicos y culturales de las clases sociales, pues objetivamente crea opinión pública a favor de un estrato u otro. Incluso, el arte por el arte, en su esterilidad retórica, las emociones o sentimientos descargados en el gesto creativo que se dan en un contexto social determinado, tienen un efecto social objetivo y pueden, en cierta forma, contribuir en el espectador a un cambio. Por ello la relevancia que el docente asuma el papel de lo político en la educación y en el arte; sin embargo, más allá de ese papel inherente, lo político debe proveer justificaciones suficientes para demostrar la necesidad en el cambio del uso social del arte.

Por tanto, el docente debe actualizarse sobre la vida política para deconstruir las teorías sociales sobre la cultura y libertad, la justicia y los derechos de las minorías (mucho tiempo atrás invisibilizados y prohibidos por el uso colonial de la razón) para así reflexionar sobre ello y abrirlos a la luz de la verdad. Debe actualizarse para contraponerse a convencionalismos y a las ideas que consideran dañina la política en el arte por suponerla un actuar subversivo que perturba el orden dado y altera el confort de las cúpulas opulentas y dominantes.

Debe poseer una consistente formación sociopolítica para que pueda actuar como agente movilizador y dinamizador de pensamientos críticos, permitiendo la diversidad de posturas y posicionamientos ideológicos pues del disenso que se genere se alimentan las disyuntivas para cuestionar y proponer; un medio que además, hace posible enlazar arte y educación con otro tipo de necesidades sociales.

Es necesario que, en su constante proceso formativo, los docentes aprendan sobre "...temas referidos a la naturaleza del poder, la ideología y la cultura, o su funcionamiento en cuanto a la construcción de ideas específicas de lo social y la producción y legitimación de formas particulares de experiencia." (Giroux, H., McLaren, P., 1998, p. 20). Pues contribuyen a la conformación del pensamiento divergente, necesario para los diálogos compartidos y las deliberaciones que se generarán con los estudiantes.

Docentes que acepten lo político como instrumento de diálogo, que abran su pensamiento y muestren sus ideologías sin temor a represalias pues deben ser ejemplos de la necesidad de la insurgencia a lo mal establecido. De ahí la pertinencia de la postura, que además viene al caso, de Sami Naïr (2006, p. 26): "No tenemos que esconder nuestras críticas, es la mejor manera de ayudar al diálogo de las civilizaciones, y abrir el debate con las sociedades civiles, con los 
grupos independientes que abogan en su país por la libertad”. Un actuar que cuesta trabajo asimilar y llevarlo a la práctica por la desconfianza de lo que pueda acarrear declararlo. En la cultura del servilismo es común suplir la voz crítica por el silencio o peor aún, por la concertación que modela y esteriliza; el docente no ortodoxo debe tener claro esta condición para volverla motivo de discusión en el aula.

Se hacen necesarios profesores que, como autoridad democrática, contribuyan a la certificación de esta última asumiéndola en sus vidas, en sus producciones y en los procesos educativos, “...con la formación de activistas políticos críticamente reflexivos comprometidos con la lucha por la justicia social y económica y la igualdad dentro y fuera del aula." (Hill, 2007, p. 223). Difícil no asumir esta responsabilidad con la que se consolida la congruencia.

En nuestras sociedades silenciadas la responsabilidad del docente político, insistiré en Henry Giroux (1990, p. 278), que tiene la capacidad de "contribuir a desvelar y sacar a la luz aquellas formas de conocimientos históricos y sojuzgados que apuntan hacia experiencias de sufrimiento, conflicto y lucha colectiva", se vuelve inobjetable. No es posible imaginar una mejor sociedad sin el cumplimiento de estas necesidades, como no es posible desligar al arte de este compromiso.

Se requiere de un docente intelectual cuyo papel asuma no únicamente desde su tradicional función cognitiva percibida históricamente como algo independiente de cuestiones de clase, cultura y poder, sino - tal la propone Antonio Gramsci (1984) — desde la destreza política y social que lleva consigo lo intelectual para transformar las tradiciones teóricas dominantes ${ }^{12}$. Se demandan, sumaría, profesores como intelectuales transformativos, como propone Giroux, (1990, p. 35), aquellos que desarrollan pedagogías contrahegemónicas.

El papel del docente es también contribuir a la desmitificación de que solo exhibiendo lo que se produce en un espacio institucionalizado o reconocido culturalmente es la ruta pertinente que lleva al reconocimiento y al éxito. "El encerramiento del arte en un gueto disciplinario, asevera Luis Camnitzer (2017), lo reduce a la producción de objetos auto-contenidos o, en su defecto, lo convierte en una práctica social superficial que no se diferencia de los servicios sociales genéricos"; una ruta convencional en la que es muy probable haya transitado el docente y no ve la razón de desestimarla. Ignora, insiste Camnitzer (2017), el hecho que el arte es una forma de pensar y de adquirir y expandir el conocimiento y que su utilidad mayor no es la de colocar piezas en un museo sino la de ayudar a usar la imaginación", así como derivarlo hacia rutas alternas más comprometidas socialmente.

12. “...el modo de ser del nuevo intelectual no puede ya consistir en la elocuencia, sino en el mezclarse activo en la vida práctica, como constructor, organizador, «persuasor permanente» precisamente por no ser puro orador” (Gramsci 1977, p. 392). 
Se requiere de un docente que devele el equívoco de que sólo existe una manera de pensar, que de fe del epistemicidio que Boaventura De Sousa Santos (2010, p. 3) define como "la destrucción de los conocimientos propios de los pueblos causada por el colonialismo europeo, que a su vez generó un imperialismo cultural y la consecuente pérdida de experiencias cognitivas.". Un compromiso que alienta al desenganche de lo único y a la esperanza de la aceptación de otras lógicas y sus capacidades.

De importancia también es el hecho que el profesor se asuma constructor de la institución (Universidad) "como un espacio público donde el dialogo intercultural sea una práctica cotidiana, la creación de otras formas estéticas configuren un acto de subversión y de resistencia frente al totalitarismo estético-epistémico de Occidente" (Bouhaben, 2018, p. 192). Un espacio donde se dé cuenta de las posibilidades reales que se tienen para trascender hacia producciones estéticas alternativas, decoloniales, en el cual, a través de la investigación y la experimentación, se promuevan nuevas formas de pensar y de pensarnos; dispuestas a reflejar desde la interculturalidad crítica las diversas realidades sociales que nos conforman.

Es necesario, finalizaría, seducir a los educadores a desafiar la razón indolente y a combatir la indiferencia al compromiso social; entendiendo esta indolencia como la resignación ante el futuro infinito y preestablecido que mantiene a la educación inmersa en un universo monocultural, y se avance hacia las ecologías liberadoras que propone De Sousa Santos (2010), sin desestimar la pedagogía para la liberación que plantea Paolo Freire (2009). Es indispensable meditar sobre el quehacer pedagógico y la responsabilidad social que implica, de tal forma que esa introspección les permita sentirse nuevamente conmovidos por el ejercicio docente.

Cumplir con este extenso listado de cualidades, difíciles de desatender, que definen al docente (idóneo), no es incorporar más obligaciones a la figura del maestro, sino que éste, a partir de ellas, se empodere de esta actitud radical, probablemente contraria a la manera en que fue instruido, de tal forma que pueda actuar en consecuencia y discrecionalidad para el logro de una educación emancipada; ese es el desafío. Cambiar el autoritarismo por la humildad, que contribuya en la formación de personalidades, forjando sujetos inclinados a la reflexión, la crítica y a la autonomía del pensamiento; que se transforme en ejemplo y guía que permita al alumno tomar el camino hacia la soberanía de su inteligencia y del yugo hegemónico, que asuma el reto de decolonizar la educación para poder aspirar a descolonizarnos.

\section{El docente ante el cambio instruccional y la conformación del currículo.}

El potencial educativo de los medios virtuales se ven cada día ejemplificados con propuestas ingeniosas que confían en el valor de lo colaborativo que, como ejercicio fundado en la empatía, el fin económico de la educación tradicional deja de tener sentido. Entre ellos destacan el Edupunk, la Educación ampliada, el Aprendizaje 
invisible, y otras experiencias educativas, que han establecido sus prácticas en la confianza, la cooperación y el carácter emprendedor de los miembros que aportan y comparten sus conocimientos por el bien común del desarrollo; que se apoyan en la filosofía del Open Social Learning y en el éxito de comunidades de Software Libre y de Código Abierto (FOSS o FLOSS, siglas de Free/Libre and Open Source Software), que permiten, además, que dicho código pueda ser modificable y se compartan conocimientos favoreciendo el trabajo colaborativo; que cuestionan las formas tradicionales de generar conocimiento (los libros, el docente, la escuela) y emplean las tecnologías como medio de aprendizaje donde los alumnos son el eje del conocimiento creado; que proponen un aprendizaje permanente fuera de los acostumbrados límites institucionales tanto temáticos como metodológicos, haciendo hincapié en que la educación puede generarse en cualquier momento, en cualquier lugar, dentro y fuera de las instituciones educativas.

En estos cambios paradigmáticos del mundo educativo vivido en la actualidad a través de la educación desescolarizada, que cada vez más vemos imponerse en el universo formativo virtual, parece que la figura del docente se diluye, incluso se especula sobre su desaparición. Hay experiencias pedagógicas virtuales y (semi)presenciales donde el docente no está presente, ni como guía, observador o evaluador; no obstante, forma parte o es el responsable directo del programa establecido que tiene como sentido la consecución de un fin educativo.

La percepción de que la ausencia del docente no afectará el programa pedagógico, por lo menos hasta ahora, es errónea; la necesidad de lo dialógico, de la orientación basada en la experiencia, de la importancia de confrontar lógicas distintas, de discutir para que el disenso encuentre su propio sentido, del diseño curricular que persigue la generación de conocimiento y el bienestar social, entre otras situaciones, requiere inexorablemente de dos o más personas, y aquí, el papel del docente sigue siendo importante; pero no el del docente tradicional, autoritario sabedor de todo, explicador y reproductor de contenidos, sino de aquel que conforma su actuar con bases críticas, que contribuye en lo educativo a través de las acciones ya descritas y se plantea el reto de la responsabilidad social como indispensable, que se desempeña modificando las lógicas erráticas, reflexiona sobre los modelos mal instrumentados y disiente con los mecanismos controladores hacedores de dogmas, y ante estas circunstancias, su figura se vuelve imprescindible.

Cerraría estas reflexiones señalando lo valioso del actuar docente desde cualquier ángulo que se plantee, incluso este último cuya presencia a veces sólo se detecta en la estructuración del currículo ofertado en la red; en este sentido redondearía el ensayo indicando lo imprescindible de este actor en la participación del diseño, elaboración y evaluación de cualquier modelo curricular. Cierto es que resulta complejo que todos los profesores puedan formar parte directa en el diseño, es necesario revertir esta justificación que ha sido la causa más común de sus ausencias. Es preciso, no únicamente incentivar su colaboración, sino comprometerla procurando su 
intervención directa o implicarlos en el trabajo colaborativo en donde a través de cuerpos colegiados (compuestos por áreas o mezclados) se discutan y propongan cambios de las deficiencias detectadas desde sus prácticas docentes. Quien sino el maestro tiene claro que muchos contenidos de los planes de estudio son obsoletos o no proporcionan ninguna razón para las reflexiones y la generación de conocimiento; por ello lo forzosa de su intervención, la que debemos comparar en importancia como la que se le otorga a cualquier otro miembro que conforma esa comisión del cambio.

Así como se requiere de la colaboración de expertos en diseño curricular que comprendan el contexto en cual se implantará el currículo, de aquellos que entienden las formas en que aprenden los estudiantes y sus necesidades, al igual que esos otros que perciban la realidad económica y política de la entidad, tanto como los demás actores administrativos, investigadores, representantes de la comunidad; la figura del docente se hace ineludible como el conocedor de las asignaturas, la complejidad del trabajo en el aula, y sobre todo como el intelectual que todo ser humano es cuando interpreta constantemente el mundo, lo dota de sentido y comparte con otros esa determinada concepción del mundo (Freire, 2005). Hechos que hacen que su participación se vuelva indispensable en la construcción de conocimiento, en su práctica y en la elaboración del currículo formal.

\section{A manera de un recuento breve}

En estos tiempo críticos dominados por la informática y los medios virtuales, el marketing cada vez más efectivo evidenciado en la consecuente explosión consumista, una sociedad estratificada por el poder económico con grandes sectores marginados, la educación se convierte en la esperanza para mitigar diferencias, por lo que deberá planearse para conformar individuos críticos y propositivos; un camino que requiere acompañarse de la figura del docente, no de aquel que ha instrumentado la educación como un medio reproductor del régimen sino como ese otro, combativo, revolucionario, que finca expectativas a partir de la realidad que vive, que no se desentiende del abuso, que no rehúye a enfrentar al que hace de la vida un dogma, al que con subterfugios y mentiras abusa y mantiene engañada a la comunidad, y acepta la docencia con la responsabilidad de contribuir en la formación del individuo comprometido con su contexto.

Visto desde esa perspectiva el que asume el mando docente en la educación artística no tiene por qué ser distinto pues, cierto es que tendría que cumplir con sus deberes tradicionales como la enseñanza de técnicas, la historia del arte y las teorías críticas que conforman el universo creativo ( si ese es el perfil del modelo educativo en que se desarrolla); sin embargo, si a esta tradicionalidad no se suma la visión reflexiva, política y crítica, el análisis de la realidad y las condiciones que provocan y mantienen la marginación social, la división de clases y género, su responsabilidad limitada a la formación para la producción de objetos de arte continuará alimentando 
las necesidades de un mercado que condiciona todo, dejando al margen aquellos otros compromisos del arte que derivan de su propia libertad, la que además de asumirse desde la forma, integrarse a otras disciplinas o a cualquier otra actividad humana se compromete con cambios que lleven a la reivindicación de los derechos elementales, a la equidad y al respeto por la diferencia; razones necesarias para impugnar la colonialidad del saber, del ser y del poder, para exigir, sin la anuencia condicionada, el mismo reconocimiento y su importancia como todo aquello que se produce desde las esferas hegemónicas.

Componentes todos que invitan actuar en consecuencia, desligándose del viejo papel instrumental y servicial a la política instituida, en un acto de verdadera transformación de reconstrucción o mejor aún de reinvención, con el cual abatir la esterilidad de una acción condicionada que asiste en la perpetuidad de lo mal establecido. Un camino que llevará al estudiante a trazarse nuevas rutas desde posturas críticas y disidentes que se empoderen de sus capacidades para que asuman, junto al docente mayores compromisos sociales. Una escuela sin esos objetivos es nula, un alumno sin esos compromisos es estéril, un docente sin esa responsabilidad es pérdida de tiempo.

\section{Referencias:}

Agirre, I. (2005). Teorías y prácticas en educación artística. Barcelona: Octaedro.

Albán, A. (2009). Artistas indígenas y afrocolombianos: Entre las memorias y las cosmovisiones. Estéticas de la re-existencias. En Arte y estética en la encrucijada descolonial / compilado por Zulma Palermo, $1^{\text {a }}$ ed. Buenos Aires: Del Signo

Belver, M. (2011). Artistas y modelos de enseñanza. En M. Acaso, M. Belver, S. Nuere, M.C. Moreno, N. Antúnez y N. Ávila, Didáctica de las Artes y la cultura visual (pp. 13-34). Madrid: Akal.

Bouhaben, M. A. (2018). La investigación artística eurocéntrica y su decolonización estético-epistémica. En A. Rodríguez y P. Alsina (coords.). Arte e Investigación II. Artnodes. No. 21: 187-196. UOC. doi:10.7238/a. v0i21.3142

Cabrera Salort, R. (2015). Formar al educador del arte: Emplazar la escuela (Ideas a debate). Imaginario Visual Investigación, UNL. Año 4 | No. 8 | Noviembre 2014 - Abril 2015. Nuevo León, México: UNL.

Canestrari, A. y Marlowe, B. (2005). From silence to dissent. Fostering critical voice in teachers. Encounter, 18(4), 41-46.

Camnitzer, L. (2017). Ni arte ni educación. Una experiencia en la que lo pedagógico vertebra lo artístico. Madrid: Catarata. 
Clark, G., Day, M. y Greer, W. (1987). Discipline Based Art Education: Becoming Students of Art, Journal of Aesthetic Education, 21, Illinois: University of Illinois Press.

De Sousa Santos, B. (2006). La Sociología de las Ausencias y la Sociología de las Emergencias: para una ecología de saberes. En publicación: Renovarla teoría crítica y reinventar la emancipación social (encuentros en Buenos Aires) (pp.2329). Buenos Aires: CLACSO.

De Sousa Santos, B. (2010). Descolonizar el saber, reinventar el poder. Uruguay: Ediciones Trilce.

Echeverría, A. (2009:218). Actos de Lenguaje. Volumen 1: La Escucha. México: Newfield Consulting.

Efland, A., Freedman, K. y Stuhr, P. (2003). La educación en el arte postmoderno, Barcelona: Paidós.

Eisner, E. (2004). El arte y la creación de la mente. Barcelona: Paidós.

Freire, P. (1974). Educación para el cambio social. Buenos Aires: Tierra Nueva.

Freire, P. (2006). Pedagogía de la indignación. (3 ${ }^{\text {a }}$ edición). Madrid: Morata.

Freire, P. (2005). Pedagogía de la esperanza: un reencuentro con la pedagogía del oprimido. Madrid: Siglo XXI.

Freire, P. (2009). La educación como práctica de la libertad. Madrid; Siglo XXI.

Giroux, H. (1990). Los profesores como intelectuales. Hacia una pedagogía crítica del aprendizaje. Barcelona: Paidós.

Giroux, H. (1997). Teoría crítica y significado de la esperanza. En A. Bás. Epistemología de la Investigación Educativa, Maestría en Sociolingüistica de la Educación Básica y Bilingüe, (2006), México: UPN.

Giroux, H. y McLaren, P. (1998). La formación de los maestros en una esfera contra-pública: notas hacia una definición, En P. McLaren, Pedagogía, identidad y poder. Los educadores frente al multiculturalismo (pp. 11-48). Santa Fe: Homo Sapiens Ediciones.

Gómez, P., González, A. y Ferreira, G, (2016). Estética(s) Decolonial(es): entrevista a Pedro Pablo Gómez. Estudios Artísticos: revista de investigación creadora, 2 (2), 119-130.

Gramsci, A. (1977). Antología. Ciudad de México: Siglo XXI. 
Gramsci, A. (1984). La formación de los intelectuales. Barcelona: Grijalbo.

Hill, D. (2007). Educación crítica para la justicia económica y social: un análisis y manifiesto marxista. En L. Huerta-Charles y M. Pruyn (Coord.), De la pedagogía crítica a la pedagogía de la revolución. Ensayos para comprender a Peter McLaren (pp. 210-253). México: Siglo XXI Editores.

Jacotot, J. (2008). Enseñanza universal. Lengua materna, [1823]. Cactus: Buenos Aires.

McLaren, P. (1984). La vida en las escuelas. Una introducción a la Pedagogía Crítica en los fundamentos de la educación. México: Siglo XXI.

Mejía, M. R. (2014). Educaciones y Pedagogías Críticas desde el Sur. Cartografía de la educación popular. México: Ed. Instituto McLaren de Pedagogía Crítica y Consejo de Educación de Adultos de América Latina.

Mignolo, W (2010). Aiesthesis decolonial. Calle 14: revista de investigación en el campo del arte. Volumen 4, núm. 4, enero-junio de 2010. Bogotá: Universidad Distrital Francisco José de Caldas.

Mignolo, W. (2019). Reconstitución epistémica/estética: la aesthesis decolonial una década después. Calle 14: revista de investigación en el campo del arte 14(25), 1432. doi: $10.14483 / 21450706.14132$

Mignolo, W. y Gómez, P. (2012). Estéticas decoloniales. Bogotá: Universidad Distrital Francisco José de Calda. Recuperado de: https://adelajusic.files.wordpress. com/2012/10/decolonial-aesthetics.pdf

Naïr, de S. (2006). Diálogo de culturas e identidades. $1^{\text {a }}$ Edición. Foro Complutense. Madrid: Editorial Complutense.

Quijano, A. (2000), Colonialidad del poder, eurocentrismo y América Latina. En E. Lander (comp.), La colonialidad del saber: eurocentrismo y ciencias sociales. Perspectivas Latinoamericanas. Buenos Aires: CLACSO, Consejo Latinoamericano de Ciencias Sociales.

Rancière, J. (2007), El maestro ignorante. Cinco lecciones para la emancipación intelectual. Buenos Aires: Libros del Zorzal.

Rorty, R. (1990). El giro lingüistico, Madrid: Paidós.

Rosique, R. (2019). Otras dimensiones para el compromiso social del arte (Un Currículo Alternativo para la Educación Superior en Artes). México: Secretaria de Cultura, UABC. 
JIMENEZ / Un docente revolucionario para la formación artística (decolonial) contemporánea

Vázquez, R. y Barrera Contreras, M. (2016). Aesthesis decolonial y los tiempos relacionales. Entrevista a Rolando Vázquez. Calle14: revista de investigación en el campo del arte, 11(18), 76-93.

Walsh, Catherine (2007). ¿Son Posibles Unas Ciencias Sociales/culturales Otras? Reflexiones En Torno a Las Epistemologías Decoloniales. Nómadas, 26, 102-113. Recuperado de: https://www.redalyc.org/pdf/1051/105115241011.pdf 